\title{
A INTERNALIZAÇÃO DOS PRINCÍPIOS DA NORMA ISO 26000: O CASO DA PETROBRAS
}

\author{
A. W. P. SILVA ${ }^{1^{*}}$ e E. S. SIQUEIRA ${ }^{2}$ \\ ${ }^{1}$ SEBRAE/RN \\ ${ }^{2}$ Universidade Federal Rural do Semi-Árido - UFERSA \\ arthurwilliamadm@hotmail.com*
}

Artigo submetido em junho/2014 e aceito em março/2015

DOI: 10.15628/holos.2015.2198

\section{RESUMO}

A ISO (International Organization for Standardization) 26000 vem contribuindo com o desenvolvimento da responsabilidade social empresarial, porém ainda mantém a natureza genérica, característica das abordagens anteriores e a ausência de indicadores. Dentro desse contexto, questiona-se se a ausência de indicadores da norma ISO 26000 compromete a avaliação e consequentemente a internalização do comportamento socialmente responsável por parte das organizações? Para responder a tal questionamento é proposto neste artigo analisar o relatório de sustentabilidade da PETROBRAS (Petróleo Brasileiro S/A) a fim de identificar de que forma os princípios da norma ISO 26000 são internalizados. O método utilizado foi o estudo de caso, sendo a empresa objeto do estudo a PETROBRAS. A técnica escolhida para a coleta dos dados foi a pesquisa documental. Os resultados e as discussões evidenciaram que existem incoerências entre os discursos sobre responsabilidade social da PETROBRAS e parte de suas ações e que a existência dessas divergências entre discurso e práticas torna-se possível graças à generalidade da norma, como também, pela ausência de indicadores.

PALAVRAS-CHAVE: Responsabilidade Social, ISO 26000, Princípios de Responsabilidade Social.

\section{THE INTERNALIZATION OF THE PRINCIPLE OF THE ISO 26000 STANDARD: THE PETROBRAS CASE}

\begin{abstract}
The ISO (International Organization for Standardization) 26000 standard has been contributing to the development of business social responsibility; however it still retains the generic nature, characteristics of previous approaches and the absence of indicators. Within this context, the objective question of this research is, does the lack of indicators for the ISO 26000 standard compromises the assessment and consequently the internalization of businesses' socially responsible behavior? To answer such a question, this article proposes to analyze PETROBRAS' (Petróleo Brasileiro S/A) sustainability report to identify how the
\end{abstract}

principle of the ISO 26000 standard are internalized. The method of research used was the case studied, and the company studied was PETROBRAS. The approach chosen for data collection was a documentary research. The results and the arguments showed that there are inconsistencies between the discourses on social responsibility of PETROBRAS and of the actions taken by them. The existence of these differences between discourse and practice becomes possible due to the generality of the standard or by the absence of indicators.

KEYWORDS: Social Responsibility, ISO 26000, Social Responsibility Principles. 


\section{INTRODUÇÃO}

Segundo Machado Filho (2002), existe certa convergência por parte dos teóricos, quando se trata da existência de uma responsabilidade social para as empresas. Para grande parte dos estudiosos, as organizações realmente possuem responsabilidades que vão além do econômico, devendo dessa forma agregar os aspectos sociais e ambientais às suas estratégias.

Porém, quando se trata do estudo sobre a natureza dessa responsabilidade social, ou seja, sua conceituação, razões, fins e limites, ocorrem grandes divergências entre as várias correntes de pensamento quanto à natureza da responsabilidade social, que advém do fato da mesma não possuir somente um caráter técnico, mas principalmente ético, o que dificulta a elaboração de qualquer tentativa de definição e delimitação dessas responsabilidades por parte dos teóricos, pois padrões éticos variam muito de uma cultura para outra. O que é aceitável para um povo, pode ser causa de repulsa para outros.

Mesmo com as dificuldades de se chegar a consensos em relação à natureza da responsabilidade social, muitos países, organizações governamentais e não governamentais vêm desenvolvendo diversas normas, certificações e orientações com o intuito de sintetizar as diversas perspectivas sobre o tema em um núcleo comum. Segundo Siqueira et al. (2009), essas sintetizações (normas, certificações e orientações) colaboram com o avanço dos estudos sobre responsabilidade social, pois ajudam a incentivar sua prática por parte das empresas, como também a divulgação de ações sociais praticadas por estas.

O ponto máximo da tentativa de sintetização das diferentes perspectivas sobre a natureza ética da responsabilidade social em um núcleo comum foi dado em 2010, com o lançamento da norma internacional ISO 26000, da qual segundo Bastos e Longo (2008), o Brasil, juntamente com a Suécia, foi um dos coordenadores no processo de formulação. O processo de elaboração dessa norma levou em conta as diversas iniciativas (normas, certificações e orientações) anteriores. Ela está em vigor desde então, e de acordo com a minuta da norma ISO (2008), lança diversos princípios sobre os aspectos ambientais, políticos, econômicos e sociais, visando orientar as empresas da sociedade contemporânea quanto às suas responsabilidades sociais.

Assim como as tentativas de sintetização anteriores, esta norma também traz os benefícios referentes a elas, e de forma bem mais abrangente, devido seu caráter internacional. Porém, segundo Siqueira et al. (2009), o processo de sintetização das diversas perspectivas sobre a natureza ética da responsabilidade social em um núcleo comum, em uma perspectiva internacional única, dificulta a sua implantação em um contexto composto por organizações singulares, devido à natureza genérica da norma. Nesse contexto, este artigo questiona: A ausência de indicadores da norma ISO 26000 compromete a avaliação e consequentemente a internalização do comportamento socialmente responsável por parte das organizações? A fim de responder ao questionamento proposto, os objetivos deste artigo são analisar o relatório de sustentabilidade da PETROBRAS a fim de identificar de que forma os princípios da norma ISO 26000 são internalizados e verificar a existência de incoerências entre os discursos sobre responsabilidade social da PETROBRAS e suas ações. 
A fim de tornar o estudo viável, as respostas à questão proposta nesse estudo foram formuladas com base no estudo de apenas uma empresa, sendo esta a Petrobras, que pertence ao segmento produtivo de exploração e produção de petróleo e gás natural no Brasil.

\section{REVISÃO BIBLIOGRÁFICA}

\subsection{Evolução histórica do conceito da responsabilidade social empresarial}

Não se pode demarcar historicamente a origem das ideias sobre responsabilidade social empresarial, pois em vários momentos da história é possível identificar vestígios de uma preocupação com o social por parte do empresariado. Porém, o início dos escritos sobre o tema está situado entre o fim do Século XIX e começo do Século XX, principalmente, entre os anos 1930 e 1940 (CARROLL, 1999).

Segundo Carroll (1999), alguns dos autores mais relevantes para o início das discussões a respeito da RSE (Responsabilidade Social Empresarial) foram: Chester Barnard (1938), que escreveu uma obra intitulada "As Funções do Executivo"; J. M. Clark (1939), que lançou um escrito, também relacionado à RSE, denominado "Controle Social de Negócios"; e por fim, Kreps Theodore (1940), autor de um livro que abordava o desempenho social corporativo, intitulado "Medição do Desempenho Social das Empresas". Porém, de acordo com o próprio Carroll (1999), as discussões sobre o tema só vieram a ganhar consistência nos anos 1960. A partir dos anos 1950 até os anos 1990, o autor faz uma análise histórica da evolução da RSE, onde são apontadas as principais fazes do desenvolvimento desse tema. Com base em sua análise, Carroll (1999) atribui a cada década, a partir de 1950, um enfoque diferente no que diz respeito à evolução da responsabilidade social corporativa. Segundo o autor, o enfoque das discussões sobre a responsabilidade social das empresas foi sendo modificado com o passar dos anos, partindo de uma abordagem fundamentalista e conceitual na década de 1950, até chegar a um momento em que a RSE serviu de base para o estudo de outros temas, na década de 1990. Como pode ser visualizado na Tabela 1, que sintetiza a evolução histórica da Responsabilidade Social Empresarial.

Tabela 1: Revisão histórica da evolução da RSE (1950-2010)

\begin{tabular}{|c|c|c|}
\hline Décadas & Enfoque & Principais autores e contribuições \\
\hline $\begin{array}{c}\text { Antes de } \\
1950\end{array}$ & $\begin{array}{c}\text { Início dos escritos sobre o } \\
\text { tema. }\end{array}$ & $\begin{array}{l}\text { Chester Barnard (1938), que escreveu a obra intitulada "As } \\
\text { Funções do Executivo"; J. M. Clark (1939), que lançou um } \\
\text { escrito, denominado “Controle Social de Negócios"; e por } \\
\text { fim, Kreps Theodore (1940) autor de um livro que abordava } \\
\text { o desempenho social corporativo, intitulado “Medição do } \\
\text { Desempenho Social das Empresas". }\end{array}$ \\
\hline $1950-1959$ & $\begin{array}{l}\text { Fundamentação e } \\
\text { conceituação da RSE. }\end{array}$ & $\begin{array}{l}\text { Howard R. Bowen (1953), afirmou que a responsabilidade } \\
\text { social "se refere às obrigações dos homens de negócios de } \\
\text { adotar orientações, tomar decisões e seguir linhas de ação, } \\
\text { que sejam compatíveis com os fins e valores de nossa } \\
\text { sociedade" (BOWEN 1957, p. 14-16). }\end{array}$ \\
\hline 1960-1969 & $\begin{array}{c}\text { Conceituação e expansão } \\
\text { da literatura. }\end{array}$ & $\begin{array}{l}\text { Conceito de RSE lançado por Keith Davis (1960, p.70) “as } \\
\text { decisões tomadas pelos dirigentes das empresas, vão além } \\
\text { dos próprios interesses técnicos e econômicos, afetando } \\
\text { todo o sistema social”; Conceito de RSE lançado por } \\
\text { McGuire (1963, p.144, apud Carrol, 1999) “a ideia de } \\
\text { responsabilidade social supõe que a corporação não tem }\end{array}$ \\
\hline
\end{tabular}




\begin{tabular}{|c|c|c|}
\hline & & $\begin{array}{c}\text { apenas obrigações econômicas e legais, mas também certas } \\
\text { responsabilidades para a sociedade que se estendem além } \\
\text { dessas obrigações". }\end{array}$ \\
\hline 1970-1979 & $\begin{array}{c}\text { Criação de modelos e } \\
\text { definições sobre o tema. }\end{array}$ & $\begin{array}{c}\text { Vários autores criaram modelos de RSE: Harold Johnson } \\
\text { (1971); George Steiner (1971); Keith Davis (1973); Preston e } \\
\text { James Post (1975); entre outros. Um dos principais modelos } \\
\text { foi o de Carrol (1979) denominado “A Pirâmide da } \\
\text { Responsabilidade Social". }\end{array}$ \\
\hline 1980-1989 & $\begin{array}{l}\text { Realização de pesquisas } \\
\text { científicas }\end{array}$ & $\begin{array}{l}\text { Principais pesquisas desenvolvidas: Philip Cochran e Robert } \\
\text { Wood (1984); Aupperle, Carroll e Hatfield (1985). Ambas } \\
\text { tinham como objetivo estudar a relação entre a RSE e o } \\
\text { desempenho financeiro das organizações. }\end{array}$ \\
\hline 1990-1999 & $\begin{array}{l}\text { A RSE serviu de base para } \\
\text { o estudo de outros temas }\end{array}$ & $\begin{array}{l}\text { Segundo Carrol (1999) os principais temas foram: ética } \\
\text { empresarial; teoria dos stakeholders; performance social } \\
\text { corporativa; e cidadania corporativa. }\end{array}$ \\
\hline 2000-2010 & $\begin{array}{c}\text { Tentativa de delimitação } \\
\text { da RSE }\end{array}$ & $\begin{array}{l}\text { A principal contribuição desse período foi a elaboração da } \\
\text { ISO } 26000 \text {. Segundo Bastos e Longo (2008) essa norma foi } \\
\text { desenvolvida pela ISO desde } 2001 \text { até a sua aprovação final } \\
\text { em } 2010 .\end{array}$ \\
\hline
\end{tabular}

Fonte: Adaptado de CARROL, 1999.

\subsection{A norma internacional de responsabilidade social: ISO 26000}

Segundo Bastos e Longo (2008), no ano 2001 a ISO recebeu solicitações enviadas por diversas organizações a fim de que o órgão avaliasse a necessidade de elaboração de uma norma internacional que tratasse do tema da responsabilidade social. Dessa forma, a referida organização coloca sobre responsabilidade do COPOLCO (Comitê de Política de Consumidor) a tarefa de realizar essa investigação. O resultado do estudo apontou para a necessidade de uma avaliação imediata do assunto pelo Comitê Máximo da ISO. Depois disso, segundo Bastos e Longo (2008),

Os estudos desenvolveram-se de setembro de 2002 a abril de 2004, culminando em relatório incentivador da construção de uma terceira geração de normas ISO, estabelecendo diretrizes e orientações promotoras do bem-estar dos diversos públicos-alvo das organizações, a cidadania, o desenvolvimento sustentável e a transparência das atividades: a futura norma ISO 26000. (BASTOS; LONGO, 2008, p. 8).

Ainda segundo Bastos e Longo (2008), o processo de formulação da ISO 26000 levou em consideração todas as normas, regulamentações e certificações elaboradas e publicadas até então, além de estar sempre aberto a discussões e contribuições das partes interessadas. A participação destas partes interessadas, dentro do processo de formulação da ISO 26000, realmente foi significativa, pois diversos segmentos sociais estiveram presentes nas reuniões e conferências sobre a ISO, e tiveram seus pontos de vista considerados no processo de formulação, tais como: governo, empresas, institutos de normalização, instituições não governamentais, trabalhadores, acadêmicos e consumidores.

De acordo com Siqueira et al. (2009), o processo de formulação da ISO 26000 ocorreu com ampla participação dos países em desenvolvimento. Essa relevância pode ser observada na escolha do Brasil para coordenar, junto com a Suécia, a elaboração da minuta do projeto. A norma internacional ISO 26000 foi aprovada e está em vigor desde 2010. 


\subsubsection{Princípios de responsabilidade social, segundo a ISO 26000}

Um dos principais objetivos na elaboração da ISO 26000 foi chegar a um consenso internacional quanto às responsabilidades sociais das empresas, pois nas últimas décadas, principalmente, a partir de 1950, o mundo corporativo tem aceitado a existência de um papel social para as organizações, porém ainda hoje não se chegou a um consenso em relação a quais responsabilidades são essas. (MACHADO FILHO, 2002, p.17).

Dessa forma, com a intenção de chegar a uma convergência dos pensamentos referentes à delimitação dessas responsabilidades, a ISO 26000 lançou, de acordo com a minuta da norma ISO (2008), um conjunto de sete princípios fundamentais que uma empresa que alega ser socialmente responsável deve aplicar.

Na Tabela 2 será apresentada a síntese das principais orientações dos sete princípios de RSE constantes na norma internacional ISO 26000, com base no texto da minuta da norma ISO (2008).

Tabela 2: Síntese das orientações dos princípios da ISO 26000.

\begin{tabular}{|c|c|}
\hline \multicolumn{2}{|c|}{ PRINCÍPIOS DE RESPONSABILIDADE SOCIAL, SEGUNDO A ISO 26000} \\
\hline $\begin{array}{c}\text { Responsabilidade por ações } \\
\text { (Accountability) }\end{array}$ & $\begin{array}{l}\text { "Uma organização deve ser responsável por seus impactos na } \\
\text { sociedade e no ambiente." (ISO, 2008, p. 16). }\end{array}$ \\
\hline Transparência & $\begin{array}{l}\text { "Uma organização deve ser transparente em suas decisões e } \\
\text { atividades que impactem na sociedade e no ambiente." (ISO, } \\
\qquad 2008, \text { p. 17). }\end{array}$ \\
\hline Comportamento ético & $\begin{array}{c}\text { "Uma organização deve comportar-se eticamente todo o } \\
\text { tempo." (ISO, 2008, p. 17). }\end{array}$ \\
\hline $\begin{array}{l}\text { Respeito pelos interesses do } \\
\text { stakeholder } \\
\end{array}$ & $\begin{array}{c}\text { "Uma organização deve respeitar e considerar os interesses de } \\
\text { seus stakeholders." (ISO, 2008, p. 18). }\end{array}$ \\
\hline Respeito pelo Estado de Direito & $\begin{array}{c}\text { "Uma organização deveria aceitar que o respeito ao estado de } \\
\text { direito é mandatório." (ISO, 2008, p. 18). }\end{array}$ \\
\hline $\begin{array}{l}\text { Respeito por normas } \\
\text { internacionais de comportamento }\end{array}$ & $\begin{array}{l}\text { "Uma organização deveria respeitar as normas internacionais } \\
\text { de comportamento, ao mesmo tempo em que adere ao } \\
\text { princípio do respeito ao estado de direito." (ISO, 2008, p. 19). }\end{array}$ \\
\hline Respeito aos direitos hul & $\begin{array}{l}\text { "Uma organização deveria respeitar os direitos humanos e } \\
\text { reconhecer sua importância e universalidade." (ISO, 2008, p. }\end{array}$ \\
\hline
\end{tabular}

19).

Fonte: Adaptado da Minuta da norma ISO 26000 (ISO, 2008, p. 16-19).

Esses princípios têm como finalidade servir de guia para uma atuação socialmente responsável das organizações que os adotam, de forma tal a orientar as decisões e ações dessas organizações a serem tomadas e executadas dentro dos padrões comportamentais que se espera de uma empresa que diz ser socialmente responsável. Vale salientar que a ISO 26000 não é uma norma com fins de certificação, mas sim de orientação, daí a opção pela criação de princípios, e não de regras.

\section{METODOLOGIA}

\subsection{Tipo da pesquisa}

Este artigo apresenta uma tipologia que combina pesquisa exploratória e explicativa. Exploratória porque o assunto e o problema propostos ainda são pouco estudados e 
sistematizados, já que a norma internacional ISO 26000 é recente, tendo sido lançada somente no ano de 2010, dessa forma, necessitando de uma investigação exploratória que de acordo com Lopes (2010) proporcione o reconhecimento dessa realidade ainda pouco estudada e traga luz sobre esses objetos e temas.

A pesquisa exploratória se deu inicialmente por meio de um questionário enviado para 80, das 97 empresas que compunham o segmento de exploração e produção de petróleo e gás natural no Brasil em 2012, segundo a lista de agentes econômicos da ANP (Agência Nacional do Petróleo, Gás Natural e Biocombustíveis, 2012), isso devido às dificuldades de acesso aos canais de comunicação de 17 destas organizações, a fim de identificar quais dessas declaram ter implementado os princípios da norma ISO 26000, porém, apesar do esforço do envio dos questionários, as respostas não foram devolvidas pelas empresas. Dessa forma, foi realizada pesquisa documental em sites e documentos oficiais das 80 empresas, a fim de atingir o mesmo objetivo do questionário, essa investigação revelou que do universo pesquisado, somente a Petróleo Brasileiro S/A - PETROBRAS declara ter implementado a ISO 26000. Além da tentativa de envio dos questionários, também se buscou realizar entrevistas nas empresas do segmento que atuam no Rio Grande do Norte, porém, nenhuma delas, em um total de 9, se dispôs a receber o pesquisador e responder aos questionamentos. Por esta razão, deu-se a escolha da PETROBRAS para ser o objeto de estudo desta pesquisa, como também, da pesquisa documental para ser a técnica de coleta de dados.

Este artigo também possui um aspecto explicativo, pois vai além da exploração de dados e informações sobre o tema da pesquisa. Ele busca utilizar os conhecimentos gerados a partir da pesquisa exploratória, para tentar explicar se a ausência de indicadores da norma ISO 26000 compromete a avaliação e consequentemente a internalização do comportamento socialmente responsável por parte das organizações. Segundo Gil (2008, p. 44), a pesquisa explicativa busca "identificar os fatores que determinam ou que contribuem para a ocorrência dos fenômenos. É o tipo que mais aprofunda o conhecimento da realidade, porque explica a razão, o porquê das coisas. Por isso, é o tipo mais complexo e delicado". Dessa forma, se mostra adequada à resolução da questão proposta neste trabalho.

\subsection{Definição da unidade de análise}

A escolha do segmento de exploração e produção de petróleo e gás natural no Brasil para ser o setor estudado, a partir do qual se buscará as repostas à questão levantada neste artigo, se deu por meio de dois fatores principais:

1) A relevância que o segmento apresenta para a economia brasileira. Segundo a Confederação Nacional da Indústria (CNI) e o Instituto Brasileiro de Petróleo, Gás e Biocombustíveis (2012), a participação relativa do setor de petróleo e gás no PIB (Produto Interno Bruto) nacional passou de apenas 3\% em 1990, para 12\% em 2010, e continua com perspectiva de crescimento para os próximos anos.

2) Os impactos ambientais que suas atividades produtivas geram. Segundo Miranda, Silva e Almeida (2010), a instalação da atividade de exploração e produção de petróleo causou uma grande transformação nos aspectos sociais, ambientais e econômicos no Brasil, principalmente nas últimas quatro décadas. De acordo com os autores, "O modo de produção e de consumo de recursos naturais, fundado na lógica de consumo ilimitado, 
gera uma acelerada degradação do ambiente, com o esgotamento dos recursos ambientais".

A empresa analisada foi a Petróleo Brasileiro S/A - PETROBRAS, sociedade de economia mista, com sede na Avenida República do Chile, 65, Rio de Janeiro - RJ, pois, por meio da pesquisa exploratória realizada, verificou-se que apenas essa empresa dentro do segmento de exploração e produção de petróleo e gás natural no Brasil, declara ter implantado a ISO 26000 como norma norteadora das suas ações de responsabilidade social.

Esse compromisso de implantação da norma internacional de responsabilidade social ISO 26000 pode ser comprovado por meio de alguns documentos emitidos pela empresa, como por exemplo: o Relatório de Sustentabilidade 2012. Nesse documento, a PETROBRAS afirma que adotou os princípios de RSE propostos na ISO 26000 na gestão das suas ações de RSE, como pode ser visto no trecho a seguir:

Além dos códigos e políticas, nossas ações são realizadas em conformidade com os compromissos assumidos. Na gestão da responsabilidade social, adotamos os princípios da norma internacional ISO 26000 e os difundimos entre nossos empregados. (PETROBRAS, 2012, p. 24).

Outro documento que comprova o compromisso da PETROBRAS com a implantação da ISO 26000 é o Acordo Coletivo de Trabalho 2011. Na Cláusula 165, a empresa se compromete com a implantação da norma, como pode ser visualizado nos trechos a seguir:

Cláusula 165 - Norma ISO 26000 - A Companhia se compromete em adotar e praticar os princípios da Norma Internacional de Responsabilidade Social ISO 26000, aprovada em 10 de Novembro de 2010, em Genebra, na Suíça. Parágrafo 1 - - A Companhia manterá a sua força de trabalho informada e disponibilizará uma cópia digital da Norma Internacional ISO 26000 a todos os seus empregados. Parágrafo 2o - A Companhia realizará uma conferência anual objetivando realizar um balanço e uma atualização das ações da Norma Internacional ISO 26000 de Responsabilidade Social. (PETROBRAS, 2011, p. 45)

A preocupação e o comprometimento com a responsabilidade social também são expressos na missão e visão da PETROBRAS, como poder ser visto abaixo:

- Missão:

Atuar de forma segura e rentável, com responsabilidade social e ambiental, nos mercados nacional e internacional, fornecendo produtos e serviços adequados às necessidades dos clientes e contribuindo para o desenvolvimento do Brasil e dos países onde atua (PETROBRAS, 2012, p. 2).

- Atributos da Visão: Entre outros tópicos estão: Ser referência em responsabilidade social e ambiental e comprometimento com o desenvolvimento sustentável (PETROBRAS, 2012).

Outro fator que levou à escolha da PETROBRAS como sendo o objeto de estudo desta pesquisa, é o fato desta ser a organização mais representativa do segmento em análise, pois segundo o site da PETROBRAS (http://www.petrobras.com.br/pt/quem-somos/perfil/), além de 
ser a líder do segmento no Brasil, a empresa está presente em 25 países, e é a 7ạ maior empresa do segmento em nível mundial. Segundo o DEPEC (Departamento de Pesquisas e Estudos Econômicos do Banco Bradesco, 2013), a PETROBRAS detém 92\% da produção nacional de petróleo, sendo os $8 \%$ restantes distribuídos entre 54 empresas. Além disso, no refino, a PETROBRAS também é líder absoluta, com $98 \%$ da capacidade de processamento nacional de petróleo.

\subsection{Técnicas de coleta de dados}

A técnica escolhida para a coleta dos dados, necessários à resolução das questões lançadas neste artigo é a pesquisa documental. Esta se apoiou no Relatório de Sustentabilidade 2012, pois foi a partir desse ano que a PETROBRAS declarou ter implementado a ISO 26000 . 0 relatório de 2013 não foi utilizado, pois até a conclusão deste artigo não tinha sido emitido e divulgado pela empresa, contudo, paralelamente também foi realizada pesquisa documental em jornais, revistas e em registros de órgãos do Poder Judiciário para verificar a existência e a natureza de práticas que constatem ou contradigam os discursos relacionados à RSE divulgados pela PETROBRAS em seu relatório de sustentabilidade 2012, no acordo coletivo de trabalho 2011 e no seu código de ética, a fim de responder a questão levantada neste trabalho.

\subsection{Método de análise de dados}

A análise dos resultados traz uma descrição das ações relatadas e ainda uma análise comparativa entre os princípios propostos na norma internacional de responsabilidade social ISO 26000, os discursos divulgados pela PETROBRAS a respeito de RSE em seu relatório de sustentabilidade 2012, no acordo coletivo de trabalho 2011 e no seu código de ética e práticas apontadas por órgãos da justiça, associações e movimentos sociais que constatem ou contradigam esses discursos, para, por meio desta análise, tentar explicar se a ausência de indicadores da norma ISO 26000 compromete a avaliação e consequentemente a internalização do comportamento socialmente responsável por parte das organizações.

\section{RESULTADOS E DISCUSSÕES}

\subsection{Responsabilidade por ações (accountability)}

Este princípio orienta que as organizações devem se responsabilizar pelos "resultados das decisões e das atividades da organização, incluindo consequências significativas, intencionais ou não e imprevistas; e os impactos significativos em stakeholders, ou seja, nos seus públicos interessados, das decisões e de ações da organização" (ISO, 2008).

$\mathrm{Na}$ análise do código de ética da PETROBRAS percebeu-se que há um direcionamento da empresa ao cumprimento deste princípio, evidenciando que a empresa afirma se comprometer em reparar os impactos gerados por suas ações e atividades, sendo estes intencionais ou imprevistos. "Reparar possíveis perdas ou prejuízos decorrentes de danos causados sob sua responsabilidade às pessoas ou comunidades afetadas, com a máxima agilidade." (PETROBRAS, 2005). 
Entretanto, de acordo com a Assessoria de Comunicação Social da Procuradoria da República no Rio de Janeiro, o MPF (Ministério Público Federal) denunciou a empresa por não ter realizado a medida reparadora adequada na implantação de um gasoduto na Baixada Fluminense, como pode ser visto no trecho a seguir.

O MPF em São João de Meriti (RJ) ofereceu denúncia contra a Petrobras, a TAG (Transportadora Associada de Gás) subsidiária S/A, o diretor técnico da TAG, Celso Luiz de Souza, e o Consórcio Malhas Sudeste Nordeste por dano ambiental durante a implantação do gasoduto Japeri-REDUC, na Baixada Fluminense. Os denunciados não realizaram o reflorestamento adequado na zona de amortecimento da REBIO (Reserva Biológica) do Tinguá, após desmatamento de 27 hectares de vegetação de Mata Atlântica, em estágio médio, para as obras. (MINISTÉRIO PÚBLICO FEDERAL, 2012)

Este fato evidencia que nem sempre o princípio é preservado, pois embora haja um discurso de respeito às orientações do princípio da responsabilidade por ações, a empresa ainda é acusada pelo MPF por não implementar uma medida reparadora de forma adequada para compensar o dano ambiental causado por suas atividades.

\subsection{Transparência}

O princípio da transparência da ISO 26000 tem como intuito impor a divulgação de informações sobre as atividades e decisões da empresa para as partes interessadas. A norma cita alguns aspectos principais a serem tratados de forma transparente por uma organização que deseja se adequar a este princípio, sendo estes os seguintes:

Sua finalidade, a natureza de suas atividades e onde são conduzidas; as normas e os critérios em relação aos quais a organização avalia seu próprio desempenho; a maneira em que suas decisões são feitas, executadas e revistas, incluindo a definição dos papéis, responsabilidades e autoridades através das funções diferentes na organização; os impactos conhecidos ou prováveis de suas decisões e atividades na sociedade e no ambiente; e a identidade de seus stakeholders e os critérios e os procedimentos usados para identificá-los, selecionar e engajar. (ISO, 2008).

Apesar de agir de acordo com o princípio da transparência da ISO 26000 na maior parcela das orientações, como ao divulgar a identidade dos seus stakeholders em seu relatório de sustentabilidade 2012, e elencar entre eles o seu público interno, a empresa é acusada pela FUP (Federação Única dos Petroleiros) de não utilizar da mesma transparência na relação com os funcionários, como pode ser visto no trecho a seguir.

No início da reunião de hoje, a FUP protestou contra a falta de transparência da Petrobras na elaboração e divulgação do PIDV (Programa de Incentivo à Demissão Voluntária) e reivindicou que sejam reabertos os concursos públicos para contratação de novos funcionários em substituição aos trabalhadores que vierem a aderir ao PIDV. A Federação também denunciou que a falta de transparência da empresa acabou prejudicando diversos trabalhadores da companhia, que fizeram as suas rescisões trabalhistas no final de 2013, sem saberem da possibilidade do lançamento deste programa e, muito menos, do seu conteúdo. (FEDERAÇÃO ÚNICA DOS PETROLEIROS, 2014) 
Através desta análise, percebe-se que grande parte das orientações sugeridas pelo princípio são atendidas pela PETROBRAS, porém nem sempre isso ocorre.

\title{
4.3 Comportamento ético
}

O princípio do comportamento ético orienta que, para possibilitar a elaboração de um código de ética adequado aos padrões éticos das comunidades onde a empresa está inserida, se faz necessário levar em consideração o pensamento dos diversos públicos interessados que compõem essas comunidades. Além de declarar ter a ética como um de seus valores organizacionais, a PETROBRAS lançou em 2005 o seu código de ética, que contou com a participação de diversos públicos interessados na sua formulação, evidenciando que a organização está buscando seguir as orientações do princípio.

Porém, apesar de afirmar ter a ética como um valor organizacional, existem fatos que revelam discrepâncias em algumas de suas ações, tais como a acusação do Júlio César Mesquita, vice-presidente da ANJ (Associação Nacional de Jornais) e responsável pelo Comitê de Liberdade de Expressão, de atitude antiética e inaceitável da PETROBRAS em relação à maneira que a empresa vem tratando os questionamentos que lhe são dirigidos pelos jornais brasileiros, como pode ser visto no trecho a seguir.

\begin{abstract}
A ANJ manifesta seu repúdio pela atitude antiética e esquiva com que a Petrobras vem tratando os questionamentos que lhe são dirigidos pelos jornais brasileiros, em particular por O Globo, Folha de S.Paulo e O Estado de S.Paulo, que nas últimas semanas publicaram reportagens sobre evidências de irregularidades e de favorecimento político em contratos assinados pela estatal e suas controladas. Numa canhestra tentativa de intimidar jornais e jornalistas, a empresa criou um blog no qual divulga as perguntas enviadas à sua assessoria de imprensa pelos jornalistas antes mesmo de publicadas as matérias às quais se referem, numa inaceitável quebra da confidencialidade que deve orientar a relação entre jornalistas e suas fontes. (ASSOCIAÇÃO NACIONAL DE JORNAIS, 2009)
\end{abstract}

Esse descontentamento pode indicar que a empresa ainda não equacionou plenamente as orientações do princípio do comportamento ético, pois mesmo afirmando ter a ética como um valor organizacional, a empresa é acusada pela ANJ de praticar atitude inaceitável e antiética.

\subsection{Respeito pelos interesses do stakeholder}

O princípio do respeito pelos interesses do stakeholder propõe que as organizações considerem que além dos interesses dos proprietários e dos colaboradores, existem outros grupos e instituições que também têm interesses, e que estes respeitem as pretensões dos seus stakeholders.

Apesar de a PETROBRAS atuar de acordo com as orientações do princípio, o que foi evidenciado a partir da análise do relatório de sustentabilidade 2012, é que existem fatos revelando que a relação de respeito para com alguns stakeholders e os seus interesses ainda não está plenamente equacionada. Tais como: A crítica do Júlio César Mesquita, vice-presidente da ANJ e responsável pelo Comitê de Liberdade de Expressão, que considerou atitude antiética e 
inaceitável da PETROBRAS à maneira que a empresa vem tratando os questionamentos que lhe são dirigidos pelos jornais brasileiros, segundo ele,

A empresa criou um blog no qual divulga as perguntas enviadas à sua assessoria de imprensa pelos jornalistas antes mesmo de publicadas as matérias às quais se referem, numa inaceitável quebra da confidencialidade que deve orientar a relação entre jornalistas e suas fontes. (ESTADÃO, 2009)

As divergências entre o discurso da PETROBRAS, constante no relatório de sustentabilidade 2012, onde a empresa afirma se preocupar com o respeito aos interesses dos seus diversos stakeholders, e algumas práticas da empresa denunciadas por outros órgãos, como a ANJ, são possíveis devido à generalidade do princípio do respeito pelos interesses dos stakeholders e ausência de indicadores que possibilitem uma análise de adequação das ações da empresa em relação às orientações do princípio.

\title{
4.5 Respeito pelo estado de direito
}

O princípio do respeito pelo estado de direito orienta que todas as organizações respeitem as leis, normas e regulamentos que incidam sobre suas atividades e relações. Através da análise do Código de ética da PETROBRAS, percebe-se que a empresa afirma possuir um forte direcionamento para a busca constante de adequação a este princípio, o que pode ser constatado no trecho a seguir.

O Sistema Petrobras reconhece e respeita as particularidades legais, sociais e culturais dos diversos ambientes, regiões e países em que atua, adotando sempre o critério de máxima realização dos direitos, cumprimento da lei, das normas e dos procedimentos internos. (PETROBRAS, 2005).

Porém, apesar deste discurso, em alguns casos a atuação da empresa não condiz com essas orientações. Tais como: $\mathrm{O}$ fato de a empresa ter sido acusada pela Polícia Federal de não respeitar a legislação sobre o tratamento e o descarte de água tóxica, como pode ser visto no trecho a seguir.

\begin{abstract}
A PF (Polícia Federal) acusa a Petrobras de despejar no oceano toneladas de resíduos tóxicos resultantes da operação de extração de petróleo de plataformas marítimas sem nenhum tipo de tratamento. $O$ inquérito da Divisão de Crimes Ambientais da PF no Rio de Janeiro, que já foi concluído e enviado ao MPF, afirma que a empresa não respeita a legislação sobre o tratamento e o descarte da água tóxica - chamada de "água de produção" ou "água negra" -, que se mistura ao óleo prospectado nas unidades marítimas de produção. Segundo o delegado Fábio Scliar, responsável pelo inquérito, as investigações mostraram que a Petrobras é "leviana" no tratamento de resíduos da extração petroleira. (VEJA, 2012)
\end{abstract}

Percebe-se, desta forma, que a falta de indicadores que possibilitem a mensuração do nível de adequação da empresa às orientações propostas no princípio do respeito ao estado de direito, dá margem para a ação definida por Carrieri e Bittencourt (2005), ou seja, a manipulação consciente das ações que compõem e atestam o discurso, a fim de veicular o relatório da melhor 
forma para defender o discurso da empresa, e este não expõe de maneira fidedigna a atuação da empresa, como pode ser percebido no caso da PETROBRAS.

\subsection{Respeito por normas internacionais de comportamento}

De acordo com a ISO 26000, além de cumprir as leis e normas nacionais, uma organização socialmente responsável deve também se comprometer com o cumprimento das leis e normas internacionais que se apliquem às suas atividades.

A análise do relatório de sustentabilidade 2012 da PETROBRAS revelou que a empresa declara estar seguindo a orientação deste princípio em vários aspectos das suas atividades, como no que tange às questões de segurança operacional, como pode ser visto no trecho a seguir: "Adotamos padrões e procedimentos operacionais internos rigorosos na prevenção de acidentes e controle de riscos, além de cumprir as normas brasileiras e internacionais de segurança em nossas instalações e transportes em terra e em mar." (PETROBRAS, 2012, p. 32). Entretanto, segundo matéria publicada em setembro de 2012 pelo movimento Causa Operária, acidentes de trabalho são rotineiros na empresa, sendo estes causados, principalmente, pelo descumprimento de normas básicas de proteção aos trabalhadores e más condições nos ambientes de trabalho. Como pode ser visto no trecho a seguir, retirado do site do movimento.

Nos últimos 12 meses, a Petrobras registou 17 óbitos por acidentes de trabalho na empresa, sendo que 15 deles com terceirizados. A última morte foi registrada na semana passada no Rio Grande do Norte. Acidente de trabalho é rotina na empresa. Segundo dados da FUP, os sindicatos receberam da Petrobras, nos últimos meses, cerca de 2.300 CAT (Comunicados de Acidente de Trabalho) com afastamento. (CAUSA OPERÁRIA, 2012)

Esta análise evidencia que a generalidade e a falta de indicadores que possibilitem à mensuração do nível de adequação da empresa às orientações do princípio do respeito por normas internacionais de comportamento que permitem a elaboração de discursos tão genéricos quanto o princípio, que defendem comportamentos socialmente responsáveis, mas que não condizem plenamente com as práticas da empresa.

\subsection{Respeito aos direitos humanos}

De acordo com o princípio do respeito aos direitos humanos constante na norma ISO 26000 (ISO, 2008), para que uma empresa possa ser considerada socialmente responsável, esta deve "respeitar os direitos humanos e aceitá-los como sendo universais".

No trecho a seguir, retirado do Relatório de Sustentabilidade 2012 da PETROBRAS, a empresa assume o compromisso com o respeito aos direitos humanos: "Nossa Política de Responsabilidade Social enfatiza o repúdio de toda e qualquer prática que caracterize desvio de conduta ou desrespeito aos direitos humanos, como trabalho infantil, forçado ou compulsório, entre outras ações". (PETROBRAS, 2012, p. 131)

Porém, apesar de assumir o compromisso com o respeito aos direitos humanos em toda a sua cadeia de negócio, independente da existência ou não de leis específicas que regulamente o assunto, afirmando adotar, na ausência das mesmas, as orientações da Declaração Universal dos Direitos Humanos, a empresa está inserida em uma lista do TST (Tribunal Superior do Trabalho), 
que expõe as 100 empresas que mais possuem processos trabalhistas ainda não pagos, a empresa estando entre as 15 mais devedoras com 29.528 processos em débito, sendo que, desse montante, 1.427 pertencem à PETROBRAS (TRIBUNAL SUPERIOR DO TRABALHO, 2012). Este fato evidencia uma falta de coerência entre o discurso da empresa, e a sua forma de atuação, pois embora haja um discurso de respeito aos direitos humanos, a questão trabalhista ainda não está devidamente equacionada, visto a quantidade de processos.

Tabela 3: Síntese dos princípios de Responsabilidade Social, discursos da Petrobras quanto à internalização dos princípios da ISO 26000 e Denúncias contra e Empresa.

\begin{tabular}{|c|c|}
\hline $\begin{array}{l}\text { Princípios da ISO } \\
26000\end{array}$ & $\begin{array}{l}\text { Principais discursos referentes à } \\
\text { internalização dos princípios }\end{array}$ \\
\hline $\begin{array}{l}\text { Responsabilidade por } \\
\text { ações } \\
\text { (Accountability) }\end{array}$ & $\begin{array}{l}\text { Um dos princípios do código de ética da } \\
\text { empresa direciona a organização ao } \\
\text { cumprimento deste princípio: "Reparar } \\
\text { possíveis perdas ou prejuízos decorrentes } \\
\text { de danos causados sob sua } \\
\text { responsabilidade às pessoas ou } \\
\text { comunidades afetadas, com a máxima } \\
\text { agilidade [...]." (PETROBRAS, 2005, p. 27). }\end{array}$ \\
\hline
\end{tabular}

A empresa em diversos trechos buscar uma atuação transparente, entre eles: Reconhecemos que nossas atividades podem afetar a vida das comunidades no entorno de nossos empreendimentos e instalações. Buscamos estabelecer uma Transparência relação respeitosa e transparente, minimizando os impactos negativos e identificando oportunidades de desenvolvimento local, sempre com respeito aos direitos humanos e à legislação vigente. (PETROBRAS, 2012, p. 104)

O lançamento em 2005 do seu código de ética, que segundo a empresa, foi formulado em conjunto com os seus stakeholder;

Afirma possuir uma estrutura de Comportamento governança corporativa bem definida, a ético fim de disseminar o comportamento ético dentro da organização. (PETROBRAS, 2012);

"Cumprir e promover o cumprimento deste Código de Ética mediante dispositivos de gestão e monitoramento [...]." (PETROBRAS, 2005, p. 14).

Reconhecimento da existência dos Respeito pelos stakeholders: Definimos os nossos interesses do stakeholder

do
públicos de interesse como grupos de indivíduos ou organizações com questões e necessidades comuns de caráter social, político, econômico, ambiental e cultural

O Ministério Público Federal denunciou a empresa em 2012 por não ter realizado a medida reparadora adequada na implantação de um gasoduto na Baixada Fluminense;

A PETROBRAS alegou ao STJ (Superior Tribunal de Justiça), não possuir responsabilidade sobre impactos ambientais e sociais causados por falhas na sua atuação na comunidade de pescadores do Paraná, mesmo com a decisão do STJ de responsabilizar a empresa por tais danos.

A Federação única dos Petroleiros protestou contra a falta de transparência da Petrobrás na elaboração e divulgação do Programa de Incentivo à Demissão Voluntária e reivindicou que sejam reabertos os concursos públicos para contratação de novos funcionários em substituição aos trabalhadores que vierem a aderir ao programa. (FEDERAÇÃO ÚNICA DOS PETROLEIROS, 2014)

Acusação do Júlio César Mesquita, vicepresidente da Associação Nacional de Jornais, de atitude antiética e inaceitável da PETROBRAS em relação à maneira que a empresa vem tratando os questionamentos que lhe são dirigidos pelos jornais brasileiros;

Os petroleiros que trabalham na bacia de Campos acusam a empresa de cometer atitudes antiéticas e anti-operárias contra os trabalhadores.

A empresa está inserida em uma lista do
Tribunal Superior do Trabalho, que expõe as
100 empresas que mais possuem processos
trabalhistas ainda não pagos, no Brasil, e a
Petrobras encontra-se entre as 15 mais
endividadas. (TRIBUNAL SUPERIOR DO


que estabelecem ou podem estabelecer relações conosco e são capazes de influenciar ou ser influenciados por nossas atividades, negócios e reputação. (PETROBRAS, 2012, p. 36)

Comprometimento com os interesses dos stakeholders: "Desenvolvemos práticas de comunicação e engajamento com os públicos de interesse com base em instrumentos de pesquisa". (PETROBRAS, 2012, p. 38)

Respeito pelo Estado de Direito

Comprometimento com o princípio: O Sistema Petrobras reconhece e respeita as particularidades legais, sociais e culturais dos diversos ambientes, regiões e países em que atua, adotando sempre o critério de máxima realização dos direitos, cumprimento da lei, das normas e dos procedimentos internos. (PETROBRAS, 2005)

A empresa declara estar seguindo a orientação deste princípio em vários aspectos das suas atividades, como no que tange às questões de segurança operacional: "Adotamos padrões e procedimentos operacionais internos

Respeito por normas internacionais de comportamento rigorosos na prevenção de acidentes e controle de riscos, além de cumprir as normas brasileiras e internacionais de segurança em nossas instalações e transportes em terra e em mar." (PETROBRAS, 2012, p. 32).

Comprometimento com princípio: “Nossa Política de Responsabilidade Social enfatiza o repúdio de toda e qualquer prática que caracterize desvio de conduta ou desrespeito aos direitos humanos, Respeito aos direitos como trabalho infantil, forçado ou humanos compulsório, entre outras ações". (PETROBRAS, 2012, p. 131)

A PETROBRAS declara ter adotado em suas atividades, práticas de disseminação do respeito aos direitos humanos em toda a sua cadeia de negócios.
TRABALHO, 2012)

Acusação do Júlio César Mesquita, vicepresidente da Associação Nacional de Jornais (ANJ), de atitude antiética e inaceitável da PETROBRAS em relação à maneira que a empresa vem tratando os questionamentos que lhe são dirigidos pelos jornais brasileiros.

A empresa foi acusada pela Polícia Federal de não respeitar a legislação sobre o tratamento e o descarte de água tóxica, causando com isso um considerável impacto ambiental. (VEJA, 2012)

A empresa está inserida em uma lista do Tribunal Superior do Trabalho, que expõe as 100 empresas que mais possuem processos trabalhistas ainda não pagos, no Brasil, e a Petrobras encontra-se entre as 15 mais endividadas. (TRIBUNAL SUPERIOR DO TRABALHO, 2012)

Segundo matéria publicada em setembro de 2012 pelo movimento Causa Operária, acidentes de trabalho são rotineiros na empresa, sendo estes causados principalmente pelo descumprimento de normas básicas de proteção aos trabalhadores e más condições nos ambientes de trabalho. (CAUSA OPERÁRIA, 2012)

A empresa está inserida em uma lista do Tribunal Superior do Trabalho, que expõe as 100 empresas que mais possuem processos trabalhistas ainda não pagos, no Brasil, e a Petrobras encontra-se entre as 15 mais endividadas. (TRIBUNAL SUPERIOR DO TRABALHO, 2012)

A PETROBRAS foi acusada em 2012 pela FNP (Federação Nacional do Petróleo) de gerar a precarização do trabalho dos colaboradores vinculados às empresas contratadas, através de diversas ações de desrespeito aos direitos humanos. (FNP, 2012)

Percebe-se que as divergências entre os discursos e as práticas identificadas na Tabela 2 decorrem da ausência de indicadores que possibilitem a mensuração do nível de aderência entre as ações praticadas pela empresa e as ações propostas pelos princípios, pois sem esses indicadores, mesmo que os princípios apontem o que deve ser feito, não se pode medir a adequação das ações às orientações dos princípios, deixando espaço para utilização da 
manipulação consciente, ação definida por Carrieri e Bittencourt (2005), para selecionar e apresentar as ações que comprovam e atestam o discurso defendido pela empresa, proporcionando a elaboração de discursos que declaram um comportamento socialmente responsável por parte das organizações, mas que não condiz plenamente com a realidade, como visto na Tabela. Comprometendo dessa forma, a avaliação do comportamento socialmente responsável das organizações.

\section{CONCLUSÃO}

Pode-se perceber, por meio da análise comparativa realizada entre os discursos da PETROBRAS sobre RSE, cada um dos sete princípios da norma ISO 26000 e algumas ações praticadas pela empresa segundo alguns órgãos públicos, associações e movimentos sociais, que existem incoerências entre os discursos sobre responsabilidade social da PETROBRAS e parte de suas ações. Nota-se que a existência dessas divergências entre discurso e práticas se torna possível graças à generalidade da norma, como também, pela ausência de indicadores.

Esta análise evidenciou, em relação à forma que os princípios da norma ISO 26000 foram internalizados, que apesar de ter sido identificado que a empresa segue grande parte das orientações dos princípios da norma, esta tem liberdade para utilizar a manipulação consciente, ação definida por Carrieri e Bittencourt (2005), para selecionar e apresentar as ações que comprovam e atestam o discurso defendido pela empresa, possibilitando a elaboração de discursos que defendem comportamentos socialmente responsáveis, mas que não condizem plenamente com as práticas da empresa, como pode ser percebido nas divergências entre os discursos da PETROBRAS constantes nesta análise, e algumas ações praticadas pela empresa e denunciadas por alguns órgãos públicos. Evidenciando que a generalidade e a falta de indicadores que possibilitem a mensuração do nível da responsabilidade social das empresas em relação aos princípios da norma ISO 26000 comprometem a avaliação e, consequentemente, a internalização do comportamento socialmente responsável por parte das organizações, pois a ausência de padrões de análise e mensuração de resultados para medir o nível de aderência entre as ações praticadas pela empresa e as ações propostas pelos princípios deixam brechas para utilização da manipulação consciente na formulação dos discursos, como visto no caso da PETROBRAS. Conclusão esta que converge com a ideia defendida por Siqueira et al. (2009), para os autores uma norma gerencial tão genérica pode gerar limitações no processo de implantação e avaliação nas organizações.

Outra constatação realizada por meio da análise é que nos discursos relacionados à maioria dos princípios de responsabilidade social propostos pela ISO 26000, a PETROBRAS não utilizou nenhum indicador, sendo estes os discursos relacionados aos princípios da: Responsabilidade por ações (Accountability); Comportamento ético; Respeito pelos interesses do stakeholder; Respeito pelo Estado de Direito; Respeito por normas internacionais de comportamento e do Respeito aos direitos humanos. O único discurso no qual a PETROBRAS utilizou algum tipo de indicador foi relacionado ao princípio da transparência. Isto indica que a dificuldade na avaliação da adequação da empresa às orientações dos princípios da ISO 26000 está presente em quase todos os princípios. 


\section{REFERÊNCIAS BIBLIOGRÁFICAS}

1. ASSOCIAÇÃO NACIONAL DE JORNAIS. ANJ repudia atitude da Petrobras: empresa divulga perguntas de jornalistas antes de matérias serem publicadas, 2009. Disponível em: <http://www.anj.org.br/sala-de-imprensa/noticias/anj-se-manifesta-contra-atitudes-dapetrobras>. Acesso em: 23 janeiro 2014.

2. AGÊNCIA NACIONAL DO PETRÓLEO, GÁS NATURAL E BIOCOMBUSTÍVEIS. Anuário Estatístico Brasileiro do Petróleo, Gás Natural e Biocombustíveis. Rio de Janeiro: ANP, 2012.

3. BASTOS, M.C.E.S., LONGO O.C. ISO - 26000 responsabilidade social como diferencial universal. In: Anais do IV Congresso Nacional de Excelência em Gestão, Niterói, 2008.

4. BOWEN, H.R. Responsabilidades sociais do homem de negócios. Rio de Janeiro: Civilização Brasileira, 1957.

5. CARRIERI, A.P., BITTENCOURT, E. Responsabilidade Social: ideologia, poder e discurso na lógica empresarial. Revista de Administração de Empresas, São Paulo, v.45, Edição Especial, p. 10-22, set-dez 2005.

6. CARROLL, A.B. Corporate Social Responsibility: evolution of a definitional construct. Business e Society, v.38, n.3, p. 268-295, setembro 1999.

7. CAUSA OPERÁRIA. Petrobras registra mais de uma morte por mês, 2012. Disponível em: <http://www.pco.org.br/movimento-operario/petrobras-registra-mais-de-uma-morte-pormes/eypa,p.html>. Acesso em: 25 janeiro 2014.

8. CONFEDERAÇÃO NACIONAL DA INDÚSTRIA. INSTITUTO BRASILEIRO DE PETRÓLEO, GÁS E BIOCOMBUSTÍVEIS. A contribuição do setor brasileiro de petróleo, gás e biocombustíveis para o desenvolvimento sustentável no país. Brasília: CNI, 2012.

9. DEPARTAMENTO DE PESQUISAS E ESTUDOS ECONÔMICOS DO BANCO BRADESCO. Petróleo e Derivados, 2013. Disponível em: http://www.economiaemdia.com.br/EconomiaEmDia/ pdf/infset_petroleo_e_derivados.pdf>._Acesso em: 12 novembro 2013.

10. ESTADÃO. ANJ vê "canhestra tentativa de intimidar jornalistas", 2009. Disponível: <http://www.estadao.com.br/noticias/impresso,anj-ve-canhestra-tentativa-de-intimidarjornalistas,384511,0.htm>. Acesso em: 23 janeiro 2014.

11. FEDERAÇÃO NACIONAL DOS PETROLEIROS. Irregularidades com terceirizados colocam Petrobrás em lista de devedores trabalhistas, 2012. Disponível em: <http://fnpetroleiros.org.br/?p=2016>. Acesso em: 25 janeiro 2014.

12. FEDERAÇÃO ÚNICA DOS PETROLEIROS. FUP cobra da Petrobrás e Petros o pagamento dos níveis para todos os assistidos do Plano Petros, 2014. Disponível em: <http://www.fup.org.br/2012/petros/2222431-fup-cobra-da-petrobras-e-petros-opagamento-dos-niveis-para-todos-os-assistidos-do-plano-petros>. Acesso em: 22 janeiro 2014.

13. GIL, A.C. Como elaborar projetos de pesquisa. 5. ed. São Paulo: Atlas, 2008.

14. ISO. ISO/TMB/WG SR N 172, 2008. Disponível em: <www.conselhos.org.br/Arquivos/Down load/Upload/84.pdf>. Acesso em: 13 setembro 2012.

15. LOPES, D. Metodologia Científica Aplicada. In: Rodrigues Júnior, G. et al. (Org.). Temas em gestão de negócios. Natal: UnP, 2010. 
16. MACHADO FILHO, C.A.P. Responsabilidade Social Corporativa e a criação de valor para as organizações: um estudo multicasos. São Paulo, 2002. Tese de doutorado-Faculdade de Economia, Administração e Contabilidade-Universidade de São Paulo, 2002.

17. MINISTÉRIO PÚBLICO FEDERAL. MPF denuncia Petrobras por dano ambiental na implantação de gasoduto na Baixada Fluminense, 2012. Disponível em: <http://www.prrj.mpf.mp.br/ frontpage/noticias/noticia_1057 >. Acesso em: 20 janeiro 2014.

18. PETROBRAS. Código de ética do Sistema Petrobras, 2005. Disponível em: <http://www.br. com.br/wps/wcm/connect/3e0b838043a79e5abce9bfecc2d0136c/codigo_de_etica_sistema _petrobras.pdf?MOD=AJPERES>. Acesso em: 25 setembro 2013.

19. Acordo Coletivo de Trabalho, 2011. Disponível em: <http://www.fup.org.br/down loads/act_2011_fup_31_10_11.pdf>. Acesso em: 26 setembro 2013.

20. . Relatório de Sustentabilidade 2012, 2012. Disponível em: <http://www.petrobras. com.br/rs2012/downloads/RS_portugu\%C3\%AAs_2012.pdf>. Acesso em: 22 setembro 2013.

21. MIRANDA, D.S., SILVA, R.G., ALMEIDA, L.B. Impactos ambientais da exploração e produção de petróleo na Bacia de Campos-RJ. Bolsista de Valor, v.1, p. 133-138, 2010.

22. SIQUEIRA, E.S., SPERS, V.R.E., BINOTTO, E., SPERS, E.E. Responsabilidade Social: possibilidade de conciliação entre o econômico e o social em uma perspectiva internacional. Porto Alegre: Análise, 2009.

23. TRIBUNAL SUPERIOR DO TRABALHO. Lista das 100 pessoas jurídicas com maior número de processos com débitos trabalhistas na Justiça do Trabalho, 2012. Disponível em: $<$ http://www.tst.jus.br/estatistica-docndt?p_auth=zYX0m9qx\&p_p_auth=4ZKLk1Bn\&p_p_id=20\&p_p_lifecycle=1\&p_p_state $=e x c l$ usive\&p_p_mode=view\&_20_struts_action=\%2Fdocument_library\%2Fget_file\&_20_groupld $=10157 \&$ 20_folderld=351894\&_20_name=10517>. Acesso em: 25 janeiro 2014.

24. VEJA. PF acusa Petrobras de poluir oceano com resíduos tóxicos, 2012. Disponível em: $<$ http://veja.abril.com.br/noticia/brasil/pf-acusa-petrobras-de-poluir-oceano-com-residuostoxicos>. Acesso em: 23 janeiro 2014. 